\title{
Unidentified patients in the emergency department: a historical cohort study
}

\author{
Kara Tastad $^{1}$ (D) Justin $\mathrm{Koh}^{2}$. Donna Goodridge ${ }^{1}$. James Stempien ${ }^{2} \cdot$ Taofiq Oyedokun $^{2}$
}

Received: 9 January 2021 / Accepted: 8 June 2021 / Published online: 17 August 2021

() The Author(s), under exclusive licence to Canadian Association of Emergency Physicians (CAEP)/ Association Canadienne de Médecine d'Urgence (ACMU) 2021

\begin{abstract}
Objectives To characterize unidentified patients presenting to a single, urban emergency department (ED) in Canada. We report their demographics, ED course, post-ED discharge outcomes, and mode of identification.

Methods We performed a retrospective chart review using descriptive analyses to assess unidentified patients admitted to Royal University Hospital and St. Paul's Hospital EDs between May 1, 2018, and April 30, 2019, in Saskatoon, Saskatchewan, Canada. We assessed demographic data, clinical presentation, mode of identification, discharge information, and major clinical outcomes.

Results Unidentified patients were disproportionately male (64.9\%), and mostly presented as Canadian Triage and Acuity Scale (CTAS) $1(41.6 \%)$ and CTAS $2(44.2 \%)$. Most patients arrived via emergency medical services (80.7\%). The most common presenting complaints were substance misuse (33.3\%) and trauma (24.6\%). The average ED length of stay was $8.7 \mathrm{~h}$ (SD 18.6). Many patients received an inpatient consult (58.8\%), and 22.3\% received support services (e.g., social work). The 30-day mortality of all patients was $13.2 \%$. Of those patients who survived to ED discharge, common dispositions included: home $(36.0 \%)$, police services (3.5\%), or emergency shelters (3.5\%). Four (3.5\%) patients returned to the hospital unidentified within the study period, and $6.7 \%$ of patients discharged from the ED returned within 48 hours.

Conclusion Unidentified patients are a high-needs demographic that present mostly with substance misuse or trauma. Repeat ED attendance, sometimes as unidentified patients again, calls for initiatives that facilitate prompt identification, better discharge planning, and linkage to social supports.
\end{abstract}

Keywords John Doe · Emergency department $\cdot$ Unidentified patient

\section{Résumé}

Objectifs Caractériser les patients non identifiés se présentant à un seul service d'urgence urbain au Canada. Nous rapportons leurs données démographiques, leur parcours aux urgences, leurs résultats après leur sortie de l'urgence et leur mode d'identification.

Kara Tastad

kara.tastad@usask.ca

Justin Koh

justin.koh@medportal.ca

Donna Goodridge

donna.goodridge@usask.ca

James Stempien

stempien@islandnet.com

Taofiq Oyedokun

Too698@mail.usask.ca
1 College of Medicine, University of Saskatchewan, 107 Wiggins Rd, Saskatoon, SK, Canada S7N 5E5

2 Department of Emergency Medicine, Royal University Hospital, Room 2646, 103 Hospital Drive, Saskatoon, SK S7N 0W8, Canada 
Méthodes Nous avons effectué un examen rétrospectif des dossiers à l'aide d'analyses descriptives pour évaluer les patients non identifiés admis à Royal University l'hôpital et St. Paul's Hospital aux urgences de l'hôpital entre le 1er mai 2018 et le 30 avril 2019, Saskatoon, Saskatchewan, au Canada. Nous avons évalué les données démographiques, la présentation clinique, le mode d'identification, les informations de sortie et les principaux résultats cliniques.

Résultats Les patients non identifiés étaient en grande partie des hommes (64.9\%) et se présentaient principalement sous la forme d'une échelle canadienne de triage et de gravité (ÉTG) 1 (41.6\%) et ÉTG 2 (44.2\%). La plupart des patients sont arrivés via les services médicaux d'urgence ( $80.7 \%$ ). Les plaintes les plus courantes étaient l'abus de substances $(33.3 \%)$ et le traumatisme (24.6\%). La durée moyenne du séjour à l'urgence était de 8,7 heures (écart-type : 18.6). De nombreux patients ont reçu une consultation interne (58.8\%) et $22.3 \%$ ont reçu des services de soutien (p. ex., travail social). La mortalité sur 30 jours de tous les patients était de $13.2 \%$. Parmi les patients qui ont survécu à la sortie du service d'urgence, les dispositions courantes comprenaient : domicile (36.0\%), services de police (3.5\%) ou refuges d'urgence $(3.5 \%)$. Quatre $(3.5 \%)$ patients sont retournés à l'hôpital sans être identifiés pendant la période d'étude, et $6.7 \%$ des patients sortis des urgences sont revenus dans les 48 heures.

Conclusion Les patients non identifiés constituent un groupe démographique à besoins élevés qui se présente principalement avec un abus de substances ou de traumatisme. La fréquentation répétée des urgences, parfois en tant que patients non identifiés à nouveau, nécessite des initiatives qui facilitent une identification rapide, une meilleure planification de la sortie et la mise en relation avec des soutiens sociaux.

\section{Clinician's capsule}

\section{What is known about this topic?}

Unidentified patients present with more severe conditions compared to identified patients in the emergency department (ED).

\section{What did this study ask?}

What are the common characteristics and clinical outcomes of unidentified patients who present to the ED?

\section{What did this study find?}

Unidentified patients are a high-needs demographic that usually presents to the ED with issues related to substance misuse and trauma.

\section{What does this study matter to clinicians?}

Unidentified patients are often unaccounted or undercounted for when resource planning despite placing a significant demand on ED services.

\section{Introduction}

Patients who present with severe injuries and altered mental status are less likely than other emergency patients to identify themselves $[1,2]$. The resulting inability to access their electronic health records has potential impacts on physician efficiency, medication errors, emergency department (ED) length of stay, and diagnostic accuracy [3, 4]. Their registration process and later mode of identification vary between institutions. The goal of prompt identification requires clear policies involving cooperation between health services and law enforcement [5]. Very few studies have been done to describe this patient population, resulting in a limited understanding of their health needs, outcomes, or mechanisms through which they may become identified, especially in Canada. More descriptive knowledge on this population will inform differential diagnoses, consultative needs, identification methods, or risk of returning to care, to advise provider decision-making. This study aimed to characterize unidentified patients who presented to the ED through reporting their demographics, ED course, post-ED discharge outcomes, and mode of subsequent identification. Particular attention was given to how this vulnerable patient group was identified, their discharge disposition, and their likelihood of returning to the ED or dying.

\section{Methods}

\section{Study design and time period}

A retrospective chart review was performed by generating records of unidentified patients seen in two Saskatoon EDs (Royal University Hospital and St. Paul's Hospital) between May 1, 2018, and April 30, 2019, from a pre-existing hospital database (see Appendix A). Patients were labeled 'unidentified' when the search for their identification had been exhausted, and their identity remained unable to be accurately determined. Detailed inclusion and exclusion criteria are reported in Appendix B. Ethics approval was obtained from the University of Saskatchewan Research Ethics Board.

\section{Study setting}

In July 2019, Saskatoon's population was 272,211 [6]. Royal University Hospital is the city's primary trauma center, with 42 ED acute care beds, 46,501 annual ED visits, and an ED admission rate of $34.8 \%$ in 2018. St. Paul's Hospital is 
a tertiary care center that serves a predominant inner-city population, with $30 \mathrm{ED}$ acute care beds, 37,508 annual ED visits, and an annual admission rate of $19.6 \%$ in 2018 .

\section{Data collection}

Trained research personnel (KT) extracted data using a standardized form - this was piloted on five patient charts (4.2\%). Data included patient demographics (age, sex), arrival data (emergency medical services (EMS), Canadian Triage Acuity Scale (CTAS), presenting complaint), services consulted in the ED, ED length of stay, identification method, and ED disposition, return to ED within $48 \mathrm{~h}$ and 30-day all-cause mortality. Data extraction was verified by another research personnel (JK) for reliability (22 charts, 19.3\%).

\section{Outcome measures}

Main outcome measures included: method of identification, mode of arrival, presenting complaint, ED discharge disposition, 48-h ED re-visit, and 30-day all-cause mortality. Detailed outcome definitions are presented in Appendix C.

\section{Data analysis}

Outcome data were analyzed descriptively in Statistical Package for the Social Sciences (SPSS) Software (version 26). Frequencies were used for categorical variables; and measures of central tendency (mean and standard deviation) for continuous variables. Patients for whom mortality could not be verified (e.g., out-of-province patients) were excluded from mortality analysis. Inter-rater reliability was calculated using Cohen's Kappa.

\section{Results}

We reviewed 118 ED visits and excluded four charts, resulting in 114 unidentified patients for our final analysis (see Appendix B). There was almost perfect agreement $(k=0.883)$ between reviewers.

\section{Demographics and initial presentation}

The unidentified patients in our study, comprising $0.14 \%$ of total ED patients seen at the study sites during the study period, presented as CTAS $1(41.6 \%)$ and CTAS $2(44.2 \%)$. The majority arrived via EMS (80.7\%), with the remainder via private vehicle $(11.4 \%)$ or walk-in $(5.3 \%)$. The mean age was 32.1 years ( $\mathrm{SD}=18.6$ ), and $64.9 \%$ were male. The top five presenting complaints (see Appendix D) were substance misuse (33.3\%), trauma (24.6\%), neurological (21.9\%), cardiovascular (7.0\%), and mental health (5.3\%). The remainder included respiratory, skin, environmental injuries, and minor complaints (7.9\%).

\section{ED course}

The average ED length of stay was $8.7 \mathrm{~h}(\mathrm{SD}=18.6)$. Initially, $58.8 \%$ of patients received one or more inpatient consults. The trauma team was most frequently consulted (42.4\%), either as a standalone service or when the ED trauma pathway was activated (i.e., automatic consults to anesthesia, general surgery, and social work). $52.7 \%$ of patients received medical consults (e.g., intensive care, subspecialty medicine, etc.), and $36.9 \%$ of patients received non-trauma surgical consults (e.g., neurosurgery, orthopedics, and plastic surgery). $7.7 \%$ of patients received psychiatry consults. Support services (e.g., social work) received $22.3 \%$ of consults. Five $(6.7 \%)$ of the 75 patients discharged (68.5\%) from the ED returned to ED care within 48 h. Four (3.5\%) unidentified patients returned to hospital as unidentified patients again.

Identification methods, ED disposition, and mortality data are listed in Table 1.

\section{Discussion}

\section{Interpretation of findings and comparison to previous studies}

Unidentified patients in our study shared three key features: (1) majority arrived via EMS and had high acuity presentations; (2) majority had substance misuse or trauma presentations; and (3) they required significant support with long average ED stays and many inpatient consults. These findings compare similarly with previous literature on the association of unidentified patients with presentations of substance abuse or trauma, and the potential for high ED service needs [1, 2, 7, 8]. Surprisingly, all patients were subsequently identified, which was a higher proportion than anticipated. The subsequent mode of identification was not recorded in one-third of unidentified patients, suggesting inconsistent documentation and implementation of hospital protocol. Most unidentified patients subsequently self-identified, likely once they were medically stable and alert. There is a need for faster and more effective identification strategies to facilitate ED triage and initial management. Although high, our mortality rate was lower than expected compared to other studies-likely due to the high substance misuse presentations $[1,7]$.

\section{Strengths and limitations}

This is the first study to describe the presentations and major outcomes of unidentified patients presenting to Canadian EDs in one western Canadian city. Data validity was ensured by having the principal investigator (TO) train both reviewers who assessed charts. Limitations include a small sample 
Table 1 Identification, ED disposition, and mortality data $(N=114)$

\begin{tabular}{|c|c|}
\hline Outcome & $n(\%)$ \\
\hline Patients identified & $114(100 \%)$ \\
\hline \multicolumn{2}{|l|}{ Identification method } \\
\hline Unknown* & $34(29.8)$ \\
\hline Self-identified & $30(26.3)$ \\
\hline Police services & $17(14.9)$ \\
\hline Family members & $9(7.9)$ \\
\hline Registered Nurse & $7(6.1)$ \\
\hline Government-issued identification & $6(5.3)$ \\
\hline Social Work & $5(4.4)$ \\
\hline Other ${ }^{\mathrm{c}}$ & $6(5.3)$ \\
\hline Admitted to hospital & $39(34.2)$ \\
\hline To OR prior to admission & $10(8.8)$ \\
\hline ICU & $19(16.7)$ \\
\hline Internal medicine & $6(5.3)$ \\
\hline Trauma services & $4(3.5)$ \\
\hline Observation & $3(2.6)$ \\
\hline Edmonton burn unit & $3(2.6)$ \\
\hline Psychiatry ward & $2(1.8)$ \\
\hline General surgery & $1(0.9)$ \\
\hline Vascular surgery & $1(0.9)$ \\
\hline Patient left against medical advice/without being seen & $14(12.3)$ \\
\hline \multicolumn{2}{|l|}{ ED discharge diagnosis $^{\mathrm{a}}$} \\
\hline Substance use disorder (suspected or confirmed) & $44(38.6)$ \\
\hline Trauma & $26(22.8)$ \\
\hline Medical & $14(12.3)$ \\
\hline Mental health & $6(5.3)$ \\
\hline Deceased & $10(8.8)$ \\
\hline Left against medical advice/without being seen & $15(13.20 .9)$ \\
\hline Unknown* & $13(11.4)$ \\
\hline Discharge disposition from the ED & $75(65.8)$ \\
\hline Home & $41(36.0)$ \\
\hline Deceased & $10(8.8)$ \\
\hline Emergency shelter & $4(3.5)$ \\
\hline Police services ${ }^{\mathrm{b}}$ & $4(3.5)$ \\
\hline Family/Friend's house & $3(2.6)$ \\
\hline Group home ${ }^{c}$ & $3(2.6)$ \\
\hline Detox Center & $1(0.9)$ \\
\hline Unknown* & $9(7.9)$ \\
\hline Patient returned to hospital as unidentified patient & $4(3.5)$ \\
\hline Mortality rate at 30 days & $15(13.2)$ \\
\hline Death in ED & $10(8.8)$ \\
\hline Death in Hospital & $4(3.5)$ \\
\hline Death post-ED discharge & $1(0.9)$ \\
\hline
\end{tabular}

ED emergency department

aAdditional breakdown of Discharge Diagnoses via ICD10 codes can be found in Table 5 in "Appendix"

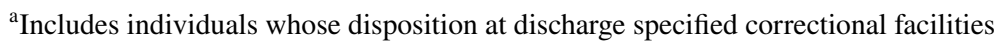

${ }^{\mathrm{b}}$ Includes individuals whose disposition was a nursing or care home facility

c"Other" represents a multitude of otherwise infrequently utilized identification methods

*"Unknown" represents patients whose method of identification, discharge diagnosis or disposition was not specified in their chart

size and site-specific data extraction. As with all retrospective studies, we relied on the accuracy of record-keeping accuracy, potentially leading to misclassification bias. Records were limited in detail as they were entered by free 
text resulting in a lack of important information. For example, many providers managing substance misuse did not specify the substance misused, nor did providers specify time taken to identify patients, limiting this population's further characterization. Another limitation is the lack of a comparison group.

\section{Clinical implications}

Although most patients self-identify themselves if given enough time, waiting for patients' physical or mental status to improve for identification likely increases the risk of harms associated with absent patient information, such as medication errors, diagnostic accuracy, and physician efficiency $[3,4]$. ED clinicians should utilize effective strategies to maximize the collection of potentially identifying information to more quickly identify this high-risk population. As most patients arrive via EMS, a thorough EMS history may provide clues for identification in a patient-centered way that prioritizes confidentiality. Strategies such as asking EMS the address the patient was picked-up from, if there were bystanders on the scene that could be contacted, or what identifiers they noticed on arrival (i.e., government issued ID, make/model of car, patients' cellphone) could help more quickly identify these patients.

Unidentified patients represent an at-risk population, evident by substance misuse presentations, emergency shelter dispositions, and return to the ED as unidentified or within 48 hours. Even though many patients were discharged 'home', this is a nonspecific term, as 'home' for many patients could refer to emergency shelters. Unidentified patients returning to hospital implies a lack of community support that have distinct opportunities to be explored by clinicians for disposition planning and support implementation. The average LOS in the ED was over eight hours, suggesting that there is a suitable time frame to implement support services. Time spent in the ED could be used to offer social support services and ascertain patient willingness to engage in harm reduction programs before discharge.

\section{Research implications}

Most patients were self-identified, which suggests healthcare professionals are required to wait for clinical improvement of patient's symptoms before they can access patient-related medical information. This a pilot descriptive study, forming the basis of future quality improvement projects to address major issues identified with this population. More descriptive exploration is needed to further characterize specific patient outcomes, such as average time to identification, how or where family members identified patients, and whether these results represent other Canadian EDs.

\section{Conclusion}

Unidentified patients are characterized by high acuity trauma and substance misuse presentations, and a high mortality rate at our center. There is insufficient documentation of the mode of identification in a significant proportion of the study patients, resulting in most identification methods being recorded as 'unknown', which calls for the need to standardize this recording process. Patients most commonly self-identified, suggesting a need for more effective strategies for quicker patient identification. Clinicians should be aware that this is a high-need population at risk for representing to the ED; therefore, support services should be implemented before disposition to help prevent repeat visits. Further studies are required to identify this high-risk group's unique needs, including the impact of early identification on clinical outcomes.

Supplementary Information The online version contains supplementary material available at https://doi.org/10.1007/s43678-021-00165-0.

Acknowledgements The authors express their sincere thanks to Ha Le (Clinical Research Support Unit), Rhonda Bryce (Clinical Research Support Unit), Aimee Goss (Health Record Services), Marissa Alarcon (Clinical Research Support Unit, Health Research Quality Improvement), and Sheree Tesch (Strategic Health Information and Performance Support) for their support and assistance over the course of this study during data collection and analysis.

Funding This project was funded by the University of Saskatchewan College of Medicine through the Dean's Summer Research Projects initiative.

\section{References}

1. Janowak CF, Dolejs S, Zarzaur BL. Who is John Doe? A casematch analysis. Am Surg. 2017;83(8):E294.

2. Bell SM, Sokhi D, Hughes T, Randall MS. Treatment of the unknown patient: insights from acute stroke. Pract Neurol. 2017; 17:453-5.

3. Campanella P, Lovato E, Marone C, Fallacara L, Mancuso A, Ricciardi W, Specchia ML. The impact of electronic health records on healthcare quality: a systematic review and meta-analysis. Eur J Public Health. 2016;26(1):60-4. https://doi.org/10.1093/eurpub/ ckv122 (Epub 2015 Jun 30 PMID: 26136462).

4. Mullins A, O’Donnell R, Mousa M, et al. Health outcomes and healthcare efficiencies associated with the use of electronic health records in hospital emergency departments: a systematic review. J Med Syst. 2020;44:200. https://doi.org/10.1007/ s10916-020-01660-0.

5. Cuomo A, Zucker H, Dreslin S (2017) Identification of unidentified patients: Model policy. Albany: New York State Division of Criminal Justice Services. https://www.criminaljustice.ny.gov/ missing/docs/DHDTC-DAL-17-03-Identification-of-Unidentifi ed-Pts-with-Policy.pdf

6. City of Saskatoon. Population growth and rate of change [Internet]. Saskatoon, SK; City of Saskatoon (2019). Accesed 26 March 2020. https://www.Blinded.ca/city-hall/our-perfo 
rmance/performance-dashboard/sustainable-growth/popul ation-growth-and-rate-change

7. Claps PJ, Berk WA. The John Doe syndrome: [diagnosis and outcome of patients unidentified at the time of emergency department admission. Am J Emerg Med. 1992;10(3):217-8.

8. Kim JJ, Kwok ES, Cook OG, Calder LA. Characterizing highly frequent users of a large Canadian urban emergency department. West J Emerg Med. 2018;19(6):926.
9. Canadian Emergency Department Information System (CEDIS), (2012). pp.1-2. Available at: https://caep.ca/wp-content/uploads/ 2016/03/nacrs_presenting_complaint_list_v2_0_en_fr_pdf_pdf. pdf. Accessed 20 March 2020. 